\title{
La mamografia en mujeres menores de 50 años reduce la mortalidad por cáncer de mama. ¿Es tiempo de extender el rastreo?
}

The Gothenburg Breast Screening Trial. First Results on Mortality, Incidence, and Mode of Detection for Women Ages 39-49 Years at Randomization. Bjurstam N, Björneld L, Duffy SW, et al. Cancer 1997;80:2091-9.

\section{Objetivo}

Estimar el efecto del rastreo (screening) mamográfico en la mortalidad por cáncer de mama (CaM) en mujeres < 50 años.

\section{Diseño}

Estudio prospectivo, randomizado y controlado con seguimiento a 10 años.

Lugar

Gothenburg, Suecia

\section{Participantes}

De la totalidad de las mujeres de Gothenburg entre 39 y 49 años ( $n=25.941)$, se randomizaron 11.724 para recibir rastreo mamográfico y 14.217 controles para comenzarlo luego del 5 to rastreo del grupo estudío (GE), 6-7 años después.

\section{Intervención}

Mamografía de alta calidad de dos incidencias cada 18 meses (30\% de una sola incidencia, cuando la densidad mamaria del estudio previo lo habilitaba). Las mamografías tuvieron una doble lectura, excepto las tres primeras rondas de rastreo. Las imágenes sospechosas se estudiaban con una mamografía suplementaria y eventual citología por punción con aguja fina. Una conferencia multidisciplinaria decidía la conducta quirúrgica.
Medición de resultados principales

Mortalidad por CaM (Los carcinomas Lobulares in situ no fueron incluídos).

\section{Resultados}

Hubo una reducción estadísticamente significativa de 45\% (IC95\% 4$69 \%$ ) en la mortalidad por CaM en el GE comparado con el grupo control (GC), y también se redujo un 35\% (IC95\% 4-56\%) el hallazgo de ganglios positivos. Estas diferencias comenzaron a apreciarse a los 6-7 años y continuaron ampliándose a lo largo del estudio. La incidencia de CaM cada 1000 personas /año fue 1.77 en el GE y algo mayor, 1.97, en el GC. La tasa de detección fue mayor en la 1er ronda de rastreo del 'GC que en el GE debido a que eran mujeres 6-7 años mayores. En las mujeres en quienes la estrategia de rastreo indicaba la necesidad de cirugía, el valor predictivo para CaM fue del $35 \%$ en la 1 er ronda del GE, aumentando hasta $70-84 \%$ en las siguientes. Las muertes por carcinoma de intervalo (hallados luego de un rastreo negativo) fueron el $55 \%$ de las muertes por CaM del GE, con una incidencia baja en los 1 ros 12 meses y notoriamente mayor entre los 12-18 meses subsiguientes al rastreo. El 72\% de las muertes del GE (13 de 18) y el 63\% del GC (25 de 40) fueron por cánceres de mama diagnosticados antes de los 50 años.

\section{Conclusiones}

El rastreo mamográfico cada 18 meses en mujeres < 50 años puede reducir la mortalidad por CaM.

\section{COMENTARIO}

Existe una gran controversia sobre la mamografía en mujeres < 50 años. Por un lado, existen diferencias en los resultados de los ensayos randomizados, y por otro, la menor incidencia de CaM en este grupo comparado con mujeres mayores hace necesario mayor $\mathrm{n}$ y tiempo de seguimiento para observar reducciones de la mortalidad. En mujeres premenopáusicas, la mayor incidencia de carcinoma de intervalo (por rápido crecimiento tumoral y < período preclínico detectable por rastreo) y la menor sensibilidad de la mamografía por mayor densidad glandular podría explicar la incidencia escasamente mayor inicial de cánceres detectados en el GE respecto al GC (de incidencia artificialmente alta, dado que el $51 \%$ de los controles se hicieron mamografías). Esto sugiere que para minimizar el número de falsos negativos, los rastreos con mamografías de alta calidad deberían ser más frecuentes que en las mujeres mayores. 0tros estudios ${ }^{1-2}$ mostraron que intervalos $>2$ años eran muy largos como para ser suficientemente efectivos. Hasta el momento los meta-análisis sólo alcanzaban significancia estadística excluyendo a criticado estudio canadiense (CNBSS) que no halló reducciones de mortalidad. Los serios cuestionamientos al CNBSS3 son: el escaso poder para detectar diferencias a los 7 años (Las diferencias en el presente estudio comenzaron a apreciarse recién a los 6-7 años), la asignación significativamente mayor de mujeres con cánceres avanzados al GEỳ por ende la inesperadamente alta sobrevida del GC (randomización posiblemente incorrecta), posible sesgo de selección (contrariamente a otros estudios se randomizaron voluntarias y no una población definida), mamografías de pobre calidad (50\% los primeros 4 años) y deficiente interpretación (42\% de "cánceres de intervalo" eran visibles en mamografías previas). Sin embargo resultaba controvertido excluir al único ensayo especialmente diseñado para mujeres de 40-49 años. Un reciente meta-análisis4confirmó la tendencia de mayores beneficios al prolongar la duración de sequimientos y mostró una significativa reducción de $18 \%$ de mortalidad (29\% incluyendo los últimos datos de los 5 ensa-

yos suecos), pero con amplios intervalos de confianza (por el escaso número de muertes por CaM en este grupo etario). El presente estudio, metodológicamente incuestionable, junto al estudio de Malmo, Suecia ${ }^{5}$ $(n=25.770)$ y al reanálisis del estudio HIP (con 18 años de seguimiento $)^{6}$, muestran por si mismos que con adecuadas mamografías y cortos intervalos de rastreo, puede reducirse significativamente $(45 \%, 36 \%$ y $25 \%$ respectivamente) la mortalidad por CaM. La tasa de mujeres que asistieron al rastreo fue de $75-85 \%$ y dado que el $33 \%$ de las muertes por CaM del GE se dio entre las que no asistieron, se estimó que la reducción de mortalidad en las que sí lo hicieran alcanzaría el $49-55 \%$ y hasta $75 \%$ con mamografía anual 7 . El Riesgo Relativo de mortalidad por todas las causas fue 0.98 (IC95\% 0.86-1.12). Dado que la mortalidad por CaM representa el $6 \%$ de todas las causas, sería esperable que la mortalidad total disminuya un 3\% (similar a lo observado). Una posible explicación de la mejor perfomance de este estudio, además de la buena calidad mamográfica, es el corto intervalo de rastreo, reduciéndose cuando es de 18-24 meses 5 y desapareciendo con 28 meses (Stockholm). En las mujeres $>50$ años se debe rastrear periódicamente a 270 para prevenir una muerte (NNR o Número Necesario para Rastrear). ${ }^{8}$ Sin bien la costoefectividad es menor en las mujeres de 40-49 años, el NNR no es 2.500 como se estimaba previamente, sino de sólo 769 mujeres. En el plano individual un rastreo menos efectivo no está exento de las consecuencias derivadas de los falsos negativos y especialmente de los falsos positivos (> biopsias benignas, $>$ costos y ansiedad), ${ }^{9}$ estimándose que por cada muerte prevenida, 63 mujeres sanas deberán profundizar los estudios $^{5}$. En conclusión las nuevas evidencias avalan extender el rastreo cada 18 meses a mujeres menores de 50 años (y posiblemente anual en un futuro si así se demostrara), pero cada paciente debería poder contar con la información necesaria sobre riesgos y beneficios como para poder decidir si se someterá o no al rastreo mamográfico. ${ }^{10}$

\section{Dr. Agustín Ciapponi}

Unidad de Medicina Familiar y Preventiva. Hospital Italiano de Buenos Aires.

Referencias

1. Tabar L, Fagerberg G ChenHH, et al. Efficacy of breast cancer screening by age: new results from the Swedish two-county trial. Cancer 1995:75:2507-17.

2. Organising Committee and Collaborators, Flun meeting. Breast cancer screening with mammography in women aged 40-49 years. Int J Cancer 1996:68:693-9.

3. Kopans DB, Feig SA. The Canadian National Breast Screening Study: A Critical Review. AJR 1993;161:755-760

4. Hendrick RE, Smith RA Rutledge JH, et al. Benefit of screening mammography in women ages 40-49: a new meta-analysis of randomized contro led trials. Monogr Natl Cancer Inst 1997:22:87-92.

5. Anderson I, Janzon L. Reduced breast cancer mortality in women under 50: updated results from the Malmo mammographic screening program. J Natl Cancer Inst Monogr 1997:22:63-68.

6. Chu KC, Smart CR, Tarone RE. Analysis of breast cancer mortality by age for the Health Insurance Plan Clinical Trial. J Natl Cancer Inst Monogr 1998;80:1125-31

7. Feig SA. Increased Benefit from Shorter Screening Mammography for Women Ages 40-49 Years. Cancer 1997:80:2035-9.

8. Salzman P, Kerlikowske K Phillips K. Cost-effectiveness of extending mammography guidelines to include women 40-49 years of age. Ann Int Med 1997:127:955-965. (Comentario

Augustovsky F, Evidencia en Atención Primaria 1997 Marzo/Abril Vol 1(2):21).

9. Fletcher S. Breast cancer screening with mammography in women under 50. BMJ 1997:314:764-5.

10. Draft NIH Consensus Statement Breast Cancer screening for women ages 40-49. http://odp.odnih.gov/consensus/statements/cdc/103/103 stmt.htlm. 